\title{
Formulation Development and Evaluation of Enteric Coated Tablets of Rabeprazole Sodium
}

\author{
B.Rama ${ }^{*}$, Shalem Raju Talluri, Grace Rathnam \\ Department of Pharmaceutics, C. L. Baid Metha College Of Pharmacy, Chennai
}

\begin{abstract}
Rabeprazole sodium is highly acid-labile and presents many formulation challenges and to protect it from acidic environment of the stomach an enteric coated tablet formulation is tried in the present study. This study is aimed to develop pharmaceutically equivalent and stable enteric-coated tablets of Rabeprazole sodium comparable to innovator product. Different Formulations of Rabeprazole core tablets were developed using mannitol as diluent and croscarmellose as super disintegrant in different proportions. Further optimized formulation was coated with varying the compositions of sub coating and enteric coating using opadry white and enteric yellow. Compatibility studies were performed for drug, physical mixture tablet which shows no interaction. From the dissolution the formulation F6 shows highest percentage of drug release. The kinetics of drug release for $F 6$ \& Innovator followed first order and ' $n$ ' value $(0.5>n<1)$ shows that the mechanism may be erosion control rate release. The f1 and f2 were found to be 3.03 and 72.01 respectively for formulation F6 and innovator product. Hence these two products were considered similar and comparable. In the accelerated stability testing carried out at $40^{\circ} \mathrm{C}$ and $75 \%$ RH for three months, no significant change in the physical properties, drug content, and dissolution rate of formulation F6 was observed. From this it can be concluded that formulation F6 developed is found to be an efficient delayed release formulations of Rabeprazole comparable to the innovator product. Thus the study fulfilled the objective of developing efficient Rabeprazole delayed release tablets.
\end{abstract}

Keywords: Rabeprazole sodium, Enteric coated tablets, Dissolution rate.

\section{Introduction}

Tablets may be defined as a solid pharmaceutical dosage forms containing drug substances with or without suitable diluents and prepared either by compression or molding methods. Some drugs resist compression in to dense particles, owing to their amorphous nature or flocculent, low-density character. Drugs with poor wetting, slow dissolution properties, intermediate to large dosage, optimum absorption high in the Gastro intestinal tract, or any combination of these features may be difficult or impossible to formulate and manufacture as a tablet. Bitter tasting drugs with an objectionable odor, or drugs that are sensitive to oxygen or atmospheric moisture may require encapsulation or entrapment prior to compression. Enteric coatings are those, which remain intact in the stomach, but will dissolve and release the contents once it reaches the small intestine. Their prime intension is to delay the release of drugs, which are inactivated by the stomach contents or may cause nausea or bleeding by irritation of gastric mucosa. Cracking of the film either during application or on storage will result in a loss of enteric properties. Therefore, consideration must be given to the mechanical properties of the applied film. Cracking problems can be effectively overcome by plasticization. Plasticizer can also be used to reduce the permeability of the polymer films to water vapor. The choice of suitable plasticizer is restricted as to non-water soluble materials because these are likely to be most effective. Rabeprazole sodium is highly acid-labile and presents many formulation challenges and to protect it from acidic environment of the stomach an enteric coated tablet formulation was carried out in the present study.

\section{Materials}

Rabeprazole sodium (Madras Pharma india), Mannitol (Roquette, France), Low substituted Hydroxy propyl cellulose (L-HPC, Shinetu Chemicals, Japan), Ethyl cellulose (Colorcon Asiapvtltd.,India). All other reagents were of analytical grade.

\section{Methods:}

Preformulation studies:

Calibration curve: Calibration curve was performed with $0.1 \mathrm{~N} \mathrm{HCl}$ and Phosphate buffer pH6.8. The results shows good Corelation coefficient with both the solvents. The results were shown in Fig 1.

\section{Drug- excipient compatibility studies:}

The compatibility studies were performed with excipients which may come in contact with the drug. The compatibility of drug with the physical mixture containing Drug, polymer and tablet were evaluated by FT-IR. The IR shows that all peaks are present in the drug are present in the physical mixture and tablet. The spectra was shown in Fig (2-5). 


\section{Determinationof bulkdensity and tapped density}

Bulkdensity is the ratio of the weight of a powder to the volume it occupies. Itis expressed as $\mathrm{gm} / \mathrm{ml}$.

Angle of Repose ${ }^{2}$ :

Angle of repose is defined as the maximum angle possible between the surface of a pile of the powder and the horizontal plane.

$$
\operatorname{Tan} \varnothing=\mathrm{h} / \mathrm{r}
$$

Where, $\mathrm{h}=$ Height of pile; $\mathrm{r}=$ radius of the base of pile; $\varnothing=$ angle of repose.

\section{Compressibility Index}

Compressibility is in directly related to the relative flowrate, cohesiveness and particle size of a powder. The compressibility of a material can be estimated from the tap and bulk density measurements ${ }^{3}$.

\section{Hausner ratio:}

Hausner ratio is a number that is correlated to the flow ability of a powder or granular material ${ }^{4}$. It is calculated by the formula

$$
H=\frac{\rho_{T}}{\rho_{B}}
$$

Where, $\rho_{\mathrm{B}}$ - freely settled bulk density of the powder

$\rho \mathrm{T}$ is the tapped bulk density of the powder.

\section{Formulation of Tablets}

Tablets were prepared by direct compression technique by mixing the drug with different concentrations of super disintegrants and other excipients (Table 1). Blended and compressed. Further Sub coating and Enteric coating was performed.

\section{Thickness}

\section{Evaluation Of Developed Tablets}

Dimensions of the tablets was measured by usingthe calibrated Vernier calipers.

Ten tablets were selected randomly from a batch average thickness was calculated. The readings are shown in the table 3.

\section{Hardness}

Ten tablets were selected randomly from a batch and hardness of the tablet was determined by using Monsanto hardness tester. The mean value and standard deviation for each batch was calculated.

\section{Disintegration Time ${ }^{7}$}

The disintegration time was determined by using USP tablet disintegration apparatus Disintegration of tablet was observed first in $0.1 \mathrm{~N} \mathrm{HCl}$ at $37 \pm 2^{\circ} \mathrm{C}$ for 2 hour and replace with Phosphate buffer pH6.8 and observe it for $1 \mathrm{hr}$. The time taken for all the tablets to disintegrate was noted. The readings were shown in table 3 .

\section{Assay $^{8,9}$}

Drug content was determined by HPLC. Phosphate buffer $\mathrm{pH}$ 6.8: Acetonitrile was used as mobile phase in the ratio of 530:470 in an Lichrosorb RP-18, 250*4.0 mm, $5 \mu$ column maintanind at a temperature of $30^{\circ} \mathrm{C}$ and the flow rate is $1.0 \mathrm{mml} / \mathrm{min}$. The injection volume is $10 \mu \mathrm{l}$.

\section{In vitro drug release studies}

In vitro studies were carried out using a USP type II dissolution apparatus. The tablet was placed in $900 \mathrm{ml}$ of $0.1 \mathrm{~N} \mathrm{HCl}$ at paddle speed of $100 \mathrm{rpm}$ maintained at $37^{\circ} \mathrm{C} \pm 0.5^{\circ} \mathrm{C}$ for $2 \mathrm{hrs} .10 \mathrm{ml}$ of Sample was taken and analyzed using UV spectrophotometer at $263 \mathrm{~nm}$. Then the dissolution medium was replaced with $\mathrm{pH} 6.8$ phosphate buffer $(900 \mathrm{ml})$ and tested for drug release for $1 \mathrm{hr}$ at same temperature and same rotation speed. $10 \mathrm{ml}$ of the samples were taken out at 10, 20, 30, 45, 60 minutes and the same volume of medium was replaced. Sample was analyzed using UV spectrophotometer at $281 \mathrm{~nm}$. The results are shown in table 6,7 and fig 13 . 


\section{Kinetics release}

Kinetic release studies were performed for best formulation and innovator to find out the order of release and mechanism of release. The readings were shown in table8.

\section{Similarity Factor and Dissimilarity Factor Calculation ${ }^{10,11}$ :}

The similarity factor (f2) was defined by CDER, FDA, and EMEA as the logarithmic reciprocal square root transformation of one plus the mean squared difference in percent dissolved between the test and reference release profiles. Dissimilarity or difference factor (f1) describes the relative error between two dissolution profiles. There are several methods for dissolution profile comparison. Similarity factor is the simplest among those methods. Moore \& Flanner proposed a model independent mathematical approach to compare the dissolution profile using two factors f1 \&f2

$$
\begin{aligned}
& \mathrm{fl}=\left\{\left[\Sigma_{\mathrm{t}=1} \mathrm{n}_{\left.\left.\Sigma \mathrm{R}_{\mathrm{t}}-\mathrm{T}_{\mathrm{t}} \Sigma\right] /\left[\Sigma_{\mathrm{t}=1} \mathrm{n}_{\mathrm{R}}\right]\right\} .100}\right.\right. \\
& \mathrm{f} 2=50 . \log \left\{1+(1 / \mathrm{n}) \Sigma_{\mathrm{t}=1} \mathrm{n}_{\left.\left(\mathrm{R}_{\mathrm{t}} \mathrm{T}_{\mathrm{t}}\right)^{2}\right]^{-0.5} .100}\right.
\end{aligned}
$$

Where ' $\mathrm{R}_{\mathrm{t}}$ "' $\mathrm{T} t$ ' are the cumulative percentage dissolved at each of the selected time point of the reference $\&$ test product respectively.

\section{Accelerated Stability Studies}

Rabeprazole sodium tablets $20 \mathrm{mg}$ were evaluated for accelerated stability studies at $40^{\circ} \mathrm{C}$ $175 \%$ RH condition ${ }^{12}$ carried out for a period of 3 months

\section{Discussion}

Seven formulations of Rabeprazole were developed by preparing core tablets using Carscarmellose as super disintegrant. Once the core tablet was optimized Further the formulations was enteric coated with varying compositions of Drug CoatL100. The compatability studies were studied by FT-IR (Fig 2-5 ). Pure drug shows peaks at $3436.4 \mathrm{~cm}^{-1}(\mathrm{Ar}-\mathrm{H}), 2810 \mathrm{~cm}^{-1}$ (Ali-H), $1584 \mathrm{~cm}^{-1}$ (aromatiC=C), $1300 \mathrm{~cm}^{-1}(\mathrm{C}-\mathrm{N}), 1092 \mathrm{~cm}^{-1}$ (C-O arylalkylether), $1009 \mathrm{~cm}^{-1}$ (S-Osulphoxide), 745 (Ar-H bending), same peaks were shown in the physical mixture i.e drug with polymers and tablets. This showsn there is no interaction between drug and polymers. In the preformulation studies the micromeritic flow properties of the API along with excipients were assessed (table 2). The results indicate good free flow of blend and further the blend was compressed into tablets.

In the formulation F1,F2 (Table 1) by using the Croscarmellose concentration at high concentration $(4 \%)$ and (2\%) shows initial burst effect in which is of only 2 mins and drug release was $99 \%$ and $93 \%$ at the end of 5 mins and 10 mins (Table 6). Since there was initial burst effect at high concentration of Croscarmellulose, the concentration was reduced to $1 \%$ in F3 Formulation (Table 1) which fulfills all the specifications of the core tablet as that of innovator. Further The core tablets formulated without superdisintegrant in F4 formulation failed to fulfillthe core specifications. Hence the F3 formulation is considered as best formulation and further coating step was processed.

For F5, F6, F7 formulations sub coating and enteric coating was done with varying concentration of 5\%, $6.5 \%$ and $7.5 \%$ of solid dispersion until the weight build upto $10 \%, 15 \%, 20 \%$ (Table 1). The F5 formulation fulfilled the core specifications but due to insufficient coating, this formulation failed in the acid resistant stage. So, increased the coating concentration.

In F6 formulation with the solid dispersion of $6.5 \% \mathrm{w} / \mathrm{w}$, coating as done until the weight build upto15\%. The F6 formulation fulfills all the specifications of core tablet, passes the acid resistant stage and also shows a good invitro release profile when compared to the innovator (I) (table 7).

Further F7 formulation was prepared with amount of coating material at concentration of $7.5 \%$ and weight build upto $20 \%$ passes the acid resistant stage, but there was a lack of drug release in the buffer stage which was only $85 \%$ when compare to that of F6 formulation. Hence formulation F6 is considered as effective formulation.

The release kinetics of Rabeprazole was developed and the data was given in (Table 8 ) indicates that F6 followed first order kinetics. When mechanism of release was analyzed by Peppas equation the ' $n$ ' value was found to be 0.5839-0.5939 indicatingthat non-fickian (Anomalous) diffusion as the release mechanism may be erosion control rate release.

The dissolution profiles of formulation F6 and innovator product were compared by calculating differential factor (f1) and similarityfactor (f2). The results of fland f2 (Table 9) were found to be 3.03 and 72.01 respectively for the comparison of dissolution profiles of formulation F6 and innovator product.Hence these two products were considered similar and comparable.

Stability studies conducted on Rabeprazole sodium enteric coated tablets storing in high density polyethylene container at $40^{\circ} \mathrm{C} / 75 \% \mathrm{RH}$ for 3 months. No significant change was observed with hardness, dissolution and assay. The drug release was $95.8 \%$ at the end of 60 mins. The drug content was $19.95 \mathrm{mg}$. 


\section{Conclusion}

Rabeprazole sodium is highly acid-labile and presents many formulation challenges and to protect it from acidic environment of the stomach an enteric coated tablet formulation is tried in the present study. The F6 formulation is quite stable with regard to drug content, physical properties and dissolution rate in the accelerated stability testing and the data is comparable with innovator product. Hence pharmaceutically equivalent and stable enteric-coated tablets of Rabeprazole sodium were prepared which are comparable to innovator product.

\section{Reference}

[1]. Martin A. Micromeritics In: Martin A. Physical pharmacy, Batimores. MD: Lippincott Williams and Wilkins, 2001 , pp 423-454.

[2]. Aulton ME, Well T1. Pharmaceutics: The science of dosage form design. London, England, Churchill livington, 1998 , pp 247.

[3]. Cooper J, Gun C. Powder flow and compaction. Inc carter SJ. Eds. Tutorial pharmacy. New Delhi, CBS publishers and distributors, 1986, pp 211-213.

[4]. Dietrich. R, Ney. Oral administration form for pyridine-2-methyl sulfinyl-1H-Benzimidazoles. US patent No: US 7041313 (B1):2006.

[5]. Tobiska.s, Kleinebuddde. Coating uniformity: Influence of atomizing air pressure. Pharm dev and tech. 2003; 8: 39-46.

[6]. Obana, GinityMc. JM. Influence of processing variables on the properties of free films prepared from aquoeus polymeric dispersions by a spray technique .Int. J. Pharm. 1995; 126: 1-10.

[7]. Pankaj R. Rege, Budhi H. Simon Kurt A. Fegely, R.Rajabi-Siahboomi. Investigation of Modified USP Disintegration Test Method for Enteric Coated Tablets. Modified release systems. 2005

[8]. Chintan N. Formulation, process, parameters, optimization and evaluation of delayed release tablets of rabeprazole sodium. Int. j. of pharm and pharmaceutical sci. 2010; 2(3):144-156.

[9]. Sanjay R. Patel. Fomulation, process parameters Opitimization and evalution of delayed release tablets of rabeprazole sodium. Int. J. of pharm and Pharmaceutical sci. 2010; 2(3): 25-69.

[10]. Costa P. An alternative method to the evaluation of similarity factor in dissolution testing. Int. J. Pharm. 2000; 5:77-83.

[11]. Moore, J.W, Flanner, H. M. Mathematical comparison of dissolution profiles. J.of PharmTech. 1996, 5:64-74.

[12]. Aoki. Preparation composition containing acid unstable physiologically active compound and process for producing same US. Patent no.US 2005/0163846 A1; 2005

Table 1: Formulation Of Rabeprazole Enteric Coated Tablets

\begin{tabular}{|l|c|c|c|c|c|c|c|}
\hline \multicolumn{1}{|c|}{ Ingredients } & F1 & F2 & F3 & F4 & F5 & F6 & F7 \\
\hline Rabeprazole Sodium & 21.5 & 21.5 & 21.5 & 21.5 & 21.5 & 21.5 & 21.5 \\
\hline Croscarmellose & 5 & 3 & 1.5 & - & 1.5 & 1.5 & 1.5 \\
\hline Hydroxy Propyl Cellulose LH-11 & 7 & 5 & 5 & 8 & 5 & 5 & 5 \\
\hline Hydroxy Propyl Cellulose LH F & 3 & 2.5 & 2.5 & 4 & 2.5 & 2.5 & 2.5 \\
\hline Mannitol & 81.25 & 86.5 & 87.75 & 84.75 & 87.5 & 87.5 & 87.5 \\
\hline Light Magnesium Oxide & 6.75 & 6 & 6.75 & 6.75 & 6.75 & 6.75 & 6.75 \\
\hline Purified Talc & 3 & 2.5 & 3 & 3 & 3 & 3 & 3 \\
\hline Magnesium Sterate & 7.5 & 8 & 7 & 7 & 7.5 & 7.5 & 7.5 \\
\hline
\end{tabular}

Coating Parameters
\begin{tabular}{|l|c|c|c|c|c|c|c|}
\hline Seal Coating & F1 & F2 & F3 & F4 & F5 & F6 & F7 \\
\hline Instacoat IC-S-010 & - & - & - & - & $4.05(6 \%)$ & $4.05(6 \%)$ & $4.05(6 \%)$ \\
\hline Isopropyl Alcohol & - & - & - & - & 27 & 27 & 27 \\
\hline Methylene Chloride & - & - & - & - & 40.05 & 40.05 & 40.05 \\
\hline Enteric coating & & & & & & & \\
\hline Drug CoatL100 & - & - & - & - & $16(5 \%)$ & $16(6.5 \%)$ & $16(7 \%)$ \\
\hline P. Talc & - & - & - & - & 3.2 & 3.2 & 3.2 \\
\hline Titanium Dioxide & - & - & - & - & 1.6 & 1.6 & 1.6 \\
\hline Triethyl Citrate & - & - & - & - & 0.6 & 0.6 & 0.6 \\
\hline Iron oxide Red(Lake) & - & - & - & - & 0.84 & 0.84 & 0.84 \\
\hline Isopropyl alcohol & - & - & - & - & 177 & 132 & 132 \\
\hline Methylene Chloride & - & - & - & - & 266 & 199 & 199 \\
\hline \%Weight Gain & & & & & $10 \%$ & $15 \%$ & $20 \%$ \\
\hline
\end{tabular}

Figure 1 : Calibration curve of Rabeprazole sodium in pH 6.8 Phosphate buffer and 0.1N HCL

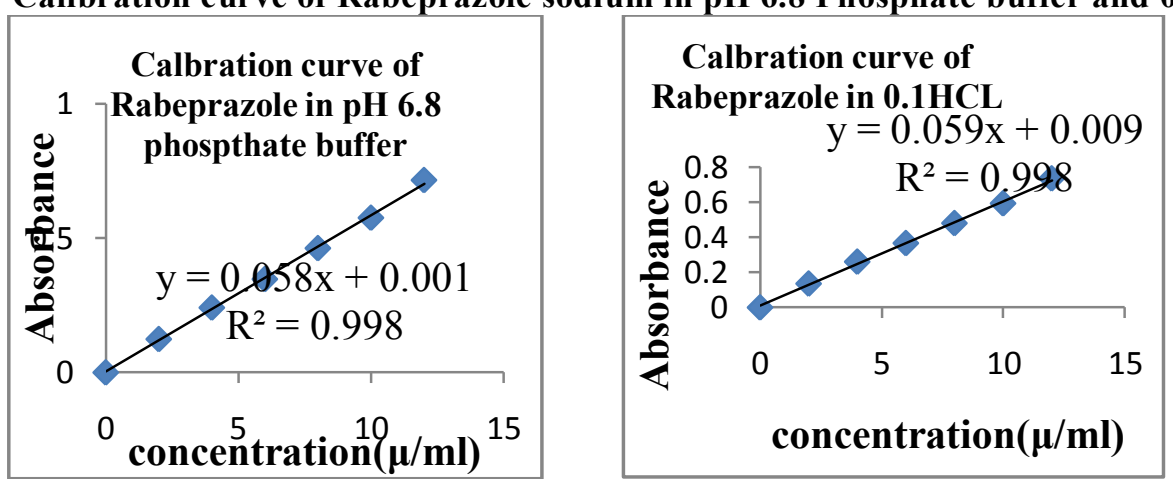


Figure 2 : FTIR Of Drug

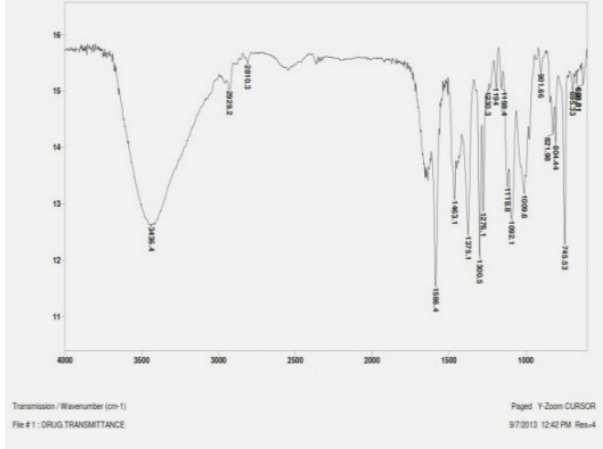

Figure 4 : FTIR Of Drug + HPC Mixture

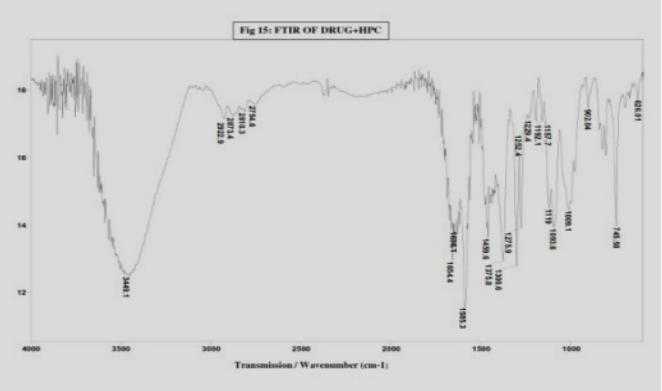

\section{Figure 3 : FTIR Of Drug +CCS Mixture}

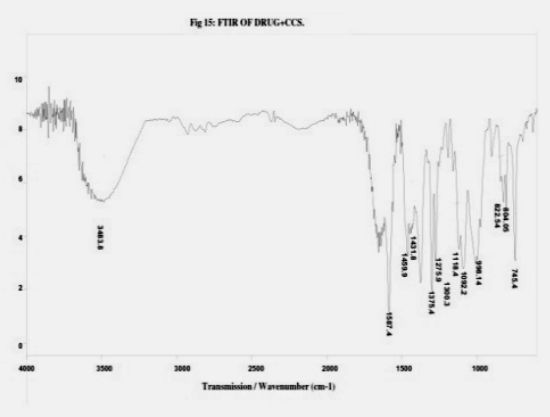

Figure 5 : FTIR Of Tablet

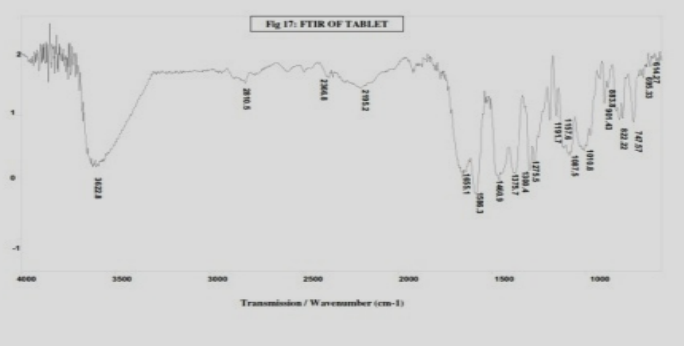

Table 2: Precompression Specifications

\begin{tabular}{|l|l|l|l|l|l|l|l|}
\hline \multicolumn{1}{|c|}{ Parameters } & \multicolumn{1}{c|}{ F1 } & \multicolumn{1}{c|}{ F2 } & \multicolumn{1}{c|}{ F3 } & \multicolumn{1}{c|}{ F4 } & \multicolumn{1}{c|}{ F5 } & \multicolumn{1}{c|}{ F6 } & F7 \\
\hline Bulk density $(\mathrm{g} / \mathrm{ml})$ & $0.31 \pm 0.1$ & $0.31 \pm 0.3$ & $0.31 \pm 0.1$ & $0.31 \pm 0.2$ & $0.32 \pm 0.1$ & $0.31 \pm 0.2$ & $0.306 \pm 0.4$ \\
\hline $\begin{array}{l}\text { Tapped } \\
\text { density }(\mathrm{g} / \mathrm{ml})\end{array}$ & $0.37 \pm 0.3$ & $0.37 \pm 0.1$ & $0.37 \pm 0.4$ & $0.36 \pm 0.1$ & $0.37 \pm 0.2$ & $0.37 \pm 0.4$ & $0.36 \pm 0.2$ \\
\hline $\begin{array}{l}\text { Compressib- } \\
\text { ilityindex(\%) }\end{array}$ & $16.0 \pm 0.1$ & $15.8 \pm 0.3$ & $15.1 \pm 0.1$ & $16.5 \pm 0.2$ & $15.5 \pm 0.2$ & $15.3 \pm 0.2$ & $15.85 \pm 0.3$ \\
\hline Hausners ratio(\%) & $1.2 \pm 0.2$ & $1.2 \pm 0.1$ & $1.17 \pm 0.2$ & $1.1 \pm 0.4$ & $1.18 \pm 0.1$ & $1.18 \pm 0.3$ & $1.18 \pm 0.1$ \\
\hline Angle of Repose & $\begin{array}{l}27.9^{0} \pm \\
0.3\end{array}$ & $\begin{array}{l}29.9^{0} \pm \\
0.3\end{array}$ & $\begin{array}{l}24.0^{0} \pm \\
0.2\end{array}$ & $\begin{array}{l}29.5^{0} \pm \\
0.1\end{array}$ & $\begin{array}{l}27.6^{0} \pm \\
0.4\end{array}$ & $\begin{array}{l}26.1^{0} \pm \\
0.3\end{array}$ & $\begin{array}{l}25.5^{0} \\
\pm 0.2\end{array}$ \\
\hline
\end{tabular}

Table 3 : Core Tablets Specifications

\begin{tabular}{|l|l|l|l|l|l|l|l|}
\hline Parameters & F1 & F2 & F3 & F4 & F5 & F6 & F7 \\
\hline $\begin{array}{l}\text { Average weight } \\
(\mathrm{mg})\end{array}$ & $135 \pm 3.5$ & $134.5 \pm 4.5$ & $135.1 \pm 4$ & $135.7 \pm 3.5$ & $134.3 \pm 5$ & $134.2 \pm 6$ & $135.9 \pm 4$ \\
\hline Thickness $(\mathrm{mm})$ & $2.9 \pm 0.02$ & $2.8 \pm 0.1$ & $2.9 \pm 0.2$ & $2.9 \pm 0.2$ & $2.7 \pm 0.3$ & $2.9 \pm 0.2$ & $2.8 \pm 0.1$ \\
\hline $\begin{array}{l}\text { Friabiity } \\
(\%)\end{array}$ & $0.23 \pm 0.09$ & $0.19 \pm 0.09$ & $0.17 \pm 0.01$ & $0.41 \pm 0.1$ & $0.27 \pm 0.02$ & $0.19 \pm 0.01$ & $0.28 \pm 0.08$ \\
\hline $\begin{array}{l}\text { Hardness } \\
\left(\mathrm{Kg} / \mathrm{cm}^{2}\right)\end{array}$ & $4.5 \pm 0.5$ & $5.10 \pm .5$ & $4.90 \pm 0.5$ & $5.50 \pm 0.5$ & $5.20 \pm 0.5$ & $5 \pm 0.5$ & $4.8 \pm 0.5$ \\
\hline $\begin{array}{l}\text { Disintegra-tion } \\
(\mathrm{min}) \text { In buffer solution }\end{array}$ & $2 \pm 1$ & $3 \pm 1$ & $9 \pm 2$ & $17 \pm 2$ & $8 \pm 2$ & $7.5 \pm 1$ & $9 \pm 2$ \\
\hline
\end{tabular}

Assay:

Table 4 : Standard Profile

\begin{tabular}{|l|c|c|c|c|c|}
\hline \multicolumn{1}{|c|}{ Title } & R.T & Area & Theoretical plate & Tailing factor & Area\% \\
\hline Check standard Inj.1 & 8.71 & 9704707 & 4463 & 1.06 & 100 \\
\hline Check standard Inj.2 & 8.72 & 9588778 & 4507 & 1.05 & 100 \\
\hline Avg & 8.71 & 9646743 & 4485 & 1.06 & 100 \\
\hline \%RSD & 0.108 & 0.85 & 0.686 & 0.0872 & 0 \\
\hline
\end{tabular}


Fig 6 :Chromatogram Of Standard 1

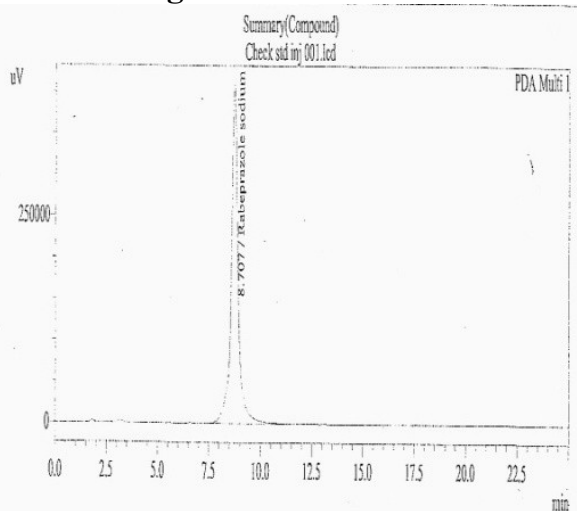

Fig 7 : Standard 2

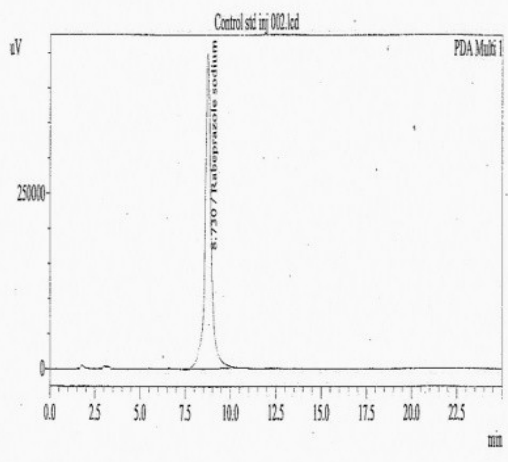

Table 5: Assay Profiles

\begin{tabular}{|c|c|c|c|c|}
\hline Title & F3 & F5 & F6 & F7 \\
\hline R.T & 8.7 & 8.73 & 8.72 & 8.7 \\
\hline Area & 1090188 & 1093162 & 10569508 & 10699508 \\
\hline Theretocal plate & 4319 & 4507 & 4507 & 4485 \\
\hline Tailing factor & 1.05 & 1.06 & 1.06 & 1.06 \\
\hline Area\% & 100 & 100 & 99.99 & 100 \\
\hline Assay(mg/tab) & 19.078473 & 18.7385 & 20.49836 & 20.278378 \\
\hline Assay\% & 95.4 & 93.7 & 102.5 & 101.5 \\
\hline
\end{tabular}

Fig 8 : Chromatogram Of F3

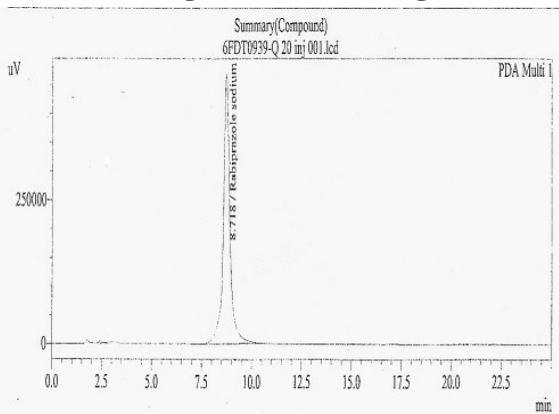

Fig 10 : Chromatogram Of F5

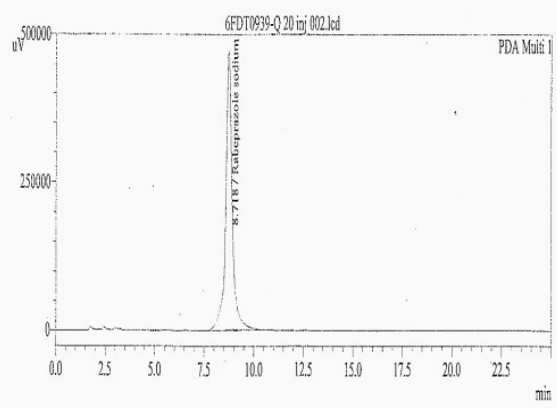

Fig 9 : Chromatogram Of F4

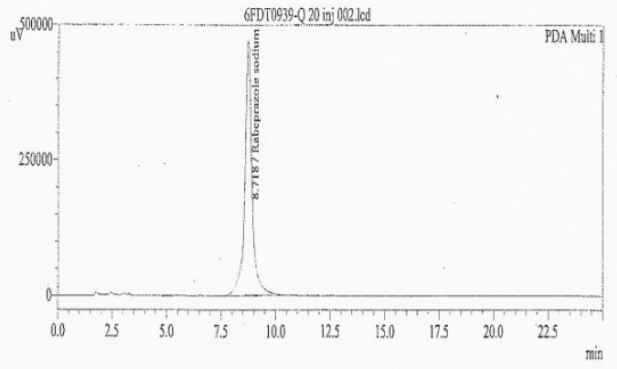

Fig 11 : Chromatogram Of F6

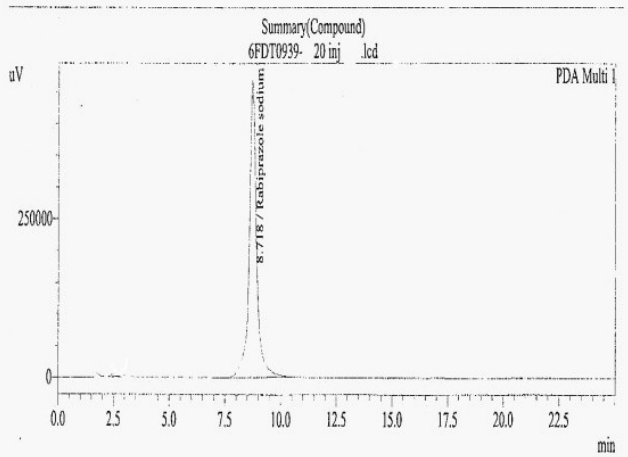

Fig 12 : Assay Chromatogram For F7

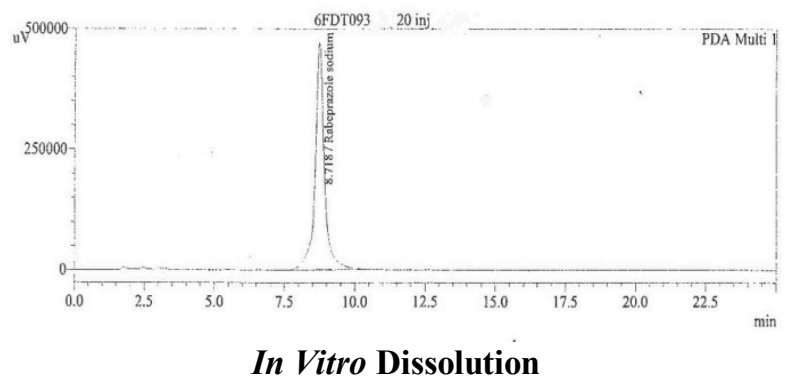

www.iosrjournals.org 
Table 6 : Cumulative \% Drug Release For Core Tablets In pH 6.8 Buffer

\begin{tabular}{|c|c|c|c|c|}
\hline \multicolumn{4}{|l|}{ Time } & \multicolumn{4}{|c|}{ \% of Drug release } \\
\cline { 2 - 5 }$(\mathrm{mins})$ & F1 & F2 & F3 & F4 \\
\hline 0 & 0 & 0 & 0 & 0 \\
\hline 5 & $99.1 \pm 0.1$ & $79.6 \pm 0.9$ & $23.3 \pm 0.6$ & $12.3 \pm 0.5$ \\
\hline 10 & - & $93.3 \pm 1.2$ & $32.1 \pm 0.9$ & $18.3 \pm 0.5$ \\
\hline 15 & & & $65.3 \pm 1.2$ & $29.8 \pm 0.9$ \\
\hline 30 & - & & $81.4 \pm 0.1$ & $42.6 \pm 0.5$ \\
\hline 45 & - & - & $89.9 \pm 0.6$ & $51.9 \pm 0.5$ \\
\hline 60 & & & $96.2 \pm 0.4$ & $55.4 \pm 0.6$ \\
\hline
\end{tabular}

Table 7 : Cumulative \% Drug Release For Coated Atblet

\begin{tabular}{|l|l|l|l|l|}
\hline & \multicolumn{4}{l|}{ \% of drug release } \\
\hline $\begin{array}{l}\text { Time } \\
\text { (mins) }\end{array}$ & F5 & F6 & F7 & I \\
\hline 0 & 0 & 0 & 0 & 0 \\
\hline 30 & $9.6 \pm 1.2$ & $1.5 \pm 0.3$ & $1.2 \pm 0.2$ & $1.9 \pm 0.6$ \\
\hline 60 & $12.8 \pm 1.4$ & $2.1 \pm 0.4$ & $2.1 \pm 0.7$ & $3.1 \pm 0.2$ \\
\hline 90 & $19.9 \pm 1.6$ & $4.9 \pm 0.2$ & $3.5 \pm 0.6$ & $4.2 \pm 0.1$ \\
\hline 120 & $34.5 \pm 0.9$ & $16.7 \pm 0.5$ & $15.4 \pm 0.9$ & $15.3 \pm 0.3$ \\
\hline 150 & - & $78.2 \pm 0.5$ & $52.4 \pm 1.3$ & $82.4 \pm 0.2$ \\
\hline 180 & - & $95.8 \pm 0.9$ & $82.5 \pm 0.7$ & $97.2 \pm 0.5$ \\
\hline
\end{tabular}

Figure 13 :In Vitro Dissolution Data For Coated Tablets (F5-F7\& Innovator)

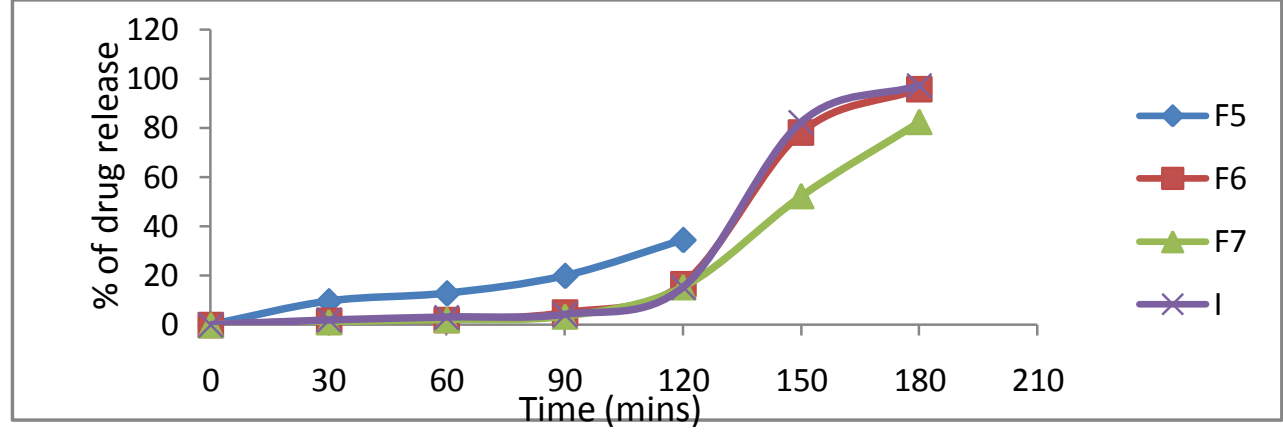

Table 8: Co-Relation Coefficient Values For F6 And I

\begin{tabular}{|l|c|l|l|l|l|}
\hline & \multicolumn{3}{|c|}{ Release kinetic model } \\
\hline Formulation & $\begin{array}{c}\text { Zero order } \\
\mathrm{R}^{2}\end{array}$ & $\begin{array}{c}\text { First order } \\
\mathrm{R}^{2}\end{array}$ & $\begin{array}{l}\text { Higuchi model } \\
\mathrm{R}^{2}\end{array}$ & \multicolumn{2}{l}{ Peppes model } \\
$\mathrm{R}^{2}$ & & $\mathrm{n}$ \\
\hline F6 & 0.8122 & 0.9906 & 0.8785 & 0.8341 & 0.5839 \\
\hline I & 0.8005 & 0.9899 & 0.8423 & 0.8443 & 0.5251 \\
\hline
\end{tabular}

Similarity Factorand Dissimilarity Factor

Table 9: F1 And F2 Value Of The Rabeprazole Sodiumtablets

\begin{tabular}{ccc} 
Time & Test Release profile & Reference Release profile \\
0 & 0 & 0 \\
$130 \mathrm{~min}$ & 29.4 & 34.1 \\
$135 \mathrm{~min}$ & 61.8 & 64.8 \\
$150 \mathrm{~min}$ & 78.2 & 82.4 \\
$165 \mathrm{~min}$ & 89.4 & 92.3 \\
$180 \mathrm{~min}$ & 95.8 & 97.2 \\
\hline
\end{tabular}

$\mathrm{fl}=3.03$

$\mathrm{f} 2=72.01$ 